\title{
Preclinical Models of Graves' Disease and Associated Secondary Complications
}

\author{
Sajad Moshkelgosha ${ }^{1 *}$, Po-Wah So ${ }^{2}$, Salvador Diaz-Cano ${ }^{3}$ and J. Paul Banga ${ }^{1}$ \\ ${ }^{I}$ Faculty of Life Sciences \& Medicine; ${ }^{2}$ Preclinical Imaging Unit, Faculty of Psychiatry, Psychology and Neuro- \\ sciences, King's College London, London, UK; ${ }^{3}$ King's College Hospital NHS Trust, Department of Pathology, \\ London, UK
}

\begin{abstract}
Autoimmune thyroid disease is the most common organ-specific autoimmune disorder which consists of two opposing clinical syndromes, Hashimoto's thyroiditis and Graves' (hyperthyroidism) disease. Graves' disease is characterized by goiter, hyperthyroidism, and the orbital complication known as Graves' orbitopathy (GO), or thyroid eye disease. The hyperthyroidism in Graves' disease is caused by stimulation of function of thyrotropin hormone receptor (TSHR), resulting from the production of agonist antibodies to the receptor. A variety of induced mouse models of Graves' disease have been developed over the past two decades, with some reproducible models leading to high disease incidence of autoimmune hyperthyroidism. However, none of the models show any signs of the orbital manifestation of GO. We have recently developed an experimental mouse model of GO induced by immunization of the plasmid encoded ligand binding domain of human TSHR cDNA by close field electroporation that recapitulates the orbital pathology in GO. As in human GO patients, immune mice with hyperthyroid or hypothyroid disease induced by anti-TSHR antibodies exhibited orbital pathology and chemosis, characterized by inflammation of orbital muscles and extensive adipogenesis leading to expansion of the orbital retrobulbar space. Magnetic resonance imaging of the head region in immune mice showed a significant expansion of the orbital space, concurrent with proptosis. This review discusses the different strategies for developing mouse models in Graves' disease, with a particular focus on GO. Furthermore, it outlines how this new model will facilitate molecular investigations into pathophysiology of the orbital disease and evaluation of new therapeutic interventions.
\end{abstract}

Keywords: Graves' disease, GO, TSHR.

\section{INTRODUCTION}

\section{Autoimmune Thyroid Disease}

Autoimmune thyroid disease (AITD) is the most common organ-specific autoimmune disorder with an incidence of $1-2 \%$ of Caucasians in the Western world [1,2]. Intriguingly, thyroid autoimmunity consists of two opposing clinical syndromes, Hashimoto's (destructive) thyroiditis and Graves' (hyperthyroidism) disease. Infiltration of the thyroid gland by lymphocytes and production of thyroid autoantibodies are the main characteristics of autoimmune thyroid diseases. In Hashimoto's thyroiditis, the immunological process is dominated by lymphocyte-mediated follicular destruction. In contrast, Graves' disease develops from immune reactivity to the thyrotropin hormone receptor (TSHR) resulting in the production of pathogenic antibodies (Abs) and follicular hyperplasia.

Epidemiological studies on twins confirmed the contribution of inherited factors in AITD [3, 4]. Recent advances in genomics provided a platform to find an association between disease incidence and susceptible genes. The currently identified genes are either disease specific for Graves' disease and Hashimoto's thyroiditis or common susceptible genes to both diseases. The loci mostly associated with AITD are categorized in three distinct groups; (i) thyroid antigens (TSHR [5] and thyroglobulin [6]), (ii) immuneresponse genes (HLA-DR3 [7] and CD40 [8]), (iii) T cell regulation (CTLA4, CD25, and PTPN22) [9]. In addition, a recent study using GWAS approach successfully genotyped 103, 875 SNPs and identified seven new loci associated with AITD [10]. Apart from genetic factors, epigenetic factors that may increase the risk of AITD have been initiated to study $[11,12]$.

*Address correspondence to this author at the Faculty of Life Science Medicine, King's College London, London, UK;

E-mail: sajad.moshkelgosha@kcl.ac.uk
The role of environmental factors in AITD is also well studied. However, the weight of environmental effects as a trigger for autoimmune responses or that enhances ongoing thyroid autoimmunity is unclear [13]. Dietary components, for a long time, have been implicated as environmental factors associated with AITD. Particularly, the level of iodide consumption has been demonstrated to play a role in onset and severity of Hashimoto's thyroiditis [14]. However, evidence suggests that increased iodide intake is not the trigger for thyroid autoimmunity but instead, is enhancer of ongoing autoimmunity [15]. Selenium is another dietary component that has been shown its contribution in AITD. Negative association of selenium with Graves' disease suggested its supplementation as one line of treatment for patients with mild orbital manifestation [16]. For Graves' disease and particularly its orbital condition, there is compelling evidence on the role of smoking as a risk factor for progression and severity of disease [17]. Deterioration of the orbital condition is considered to be due to hypoxia induction [18]. Similar to other autoimmune diseases, viral and bacterial infections are important risk factors among the environmental factors in AITD [19]. Infection with Yersinia enterocolitica has been implicated as a trigger for Graves' disease. Recent studies in our laboratory using anti-TSHR thyroid stimulating mAbs confirmed molecular mimicry as one of the mechanisms by which $Y$. enterocolitica porins crossreact to TSHR [20].

\section{Graves' Disease and Graves' Orbitopathy (GO)}

Autoimmune hyperthyroidism, also known as Graves' disease results from activating Abs to TSHR on thyroid follicular cells, which are able to emulate the actions of thyroid stimulating hormone (TSH). Stimulation of TSHR by Abs makes the negative feedback regulation counterproductive, as the stimulating Abs persistently activate the thyroid gland. Graves' orbitopathy is a common chronic extrathyroidal manifestation of Graves' disease. GO is characterized by an increase in orbital adipose tissue and an accumulation of glycosaminoglycans (GAGs); in some cases there is 
also expansion of extraorbital muscles causing increased volumes of orbital tissue [21].

Proptosis, periorbital swelling and extraocular muscle dysfunction are clinical symptoms of GO that can be explained by volume expansion in the bony orbital structure. Patients with overt Graves' orbitopathy frequently present with upper eyelid retraction, proptosis and edema along with congestion of the periorbital tissues and conjunctivae [22]. In most cases, the onset of Graves' orbitopathy is concomitant with the onset of hyperthyroidism, but orbital complication may present prior to, or following the presentation of hyperthyroidism [23].

\section{Thyrotropin Stimulating Hormone Receptor (TSHR)}

The TSHR is a member of G protein-coupled receptor family with 7-transmembrane domains. The TSHR of 764 amino acids comprises of three main parts, starting with residues 1 to 21 , which form the signal peptide of TSHR. There is a large glycosylated ectodomain with 394-aminoacid encoded by 9 exons. The last is the 7-transmembrane domain and cytoplasmic tail of 350 amino acids, encoded by a single exon. The transmembrane region is comprised of 281 amino acids with the cytoplasmic region of 69 residues. The highly glycosylated ectodomain consists of two smaller domains of ten leucine rich regions (LRR, amino acids 22 - 316) and the "cleavage" or the "hinge" region (amino acids 316 to 366) [24]. The LRR interacts with the ligand TSH and with antibodies to TSHR.

Intramolecular cleavage within the hinge region represented by residues 316-366 [25] divides TSHR into two distinct subunits. The secretory region is known as the A-subunit, whilst the B-subunit comprises of remainder of the protein including the hinge region, a short membrane-anchored region and the intracellular portion [2628]. Evidence from thyrocyte culture shows that the A-subunit is shed into the medium $[29,30]$. Importantly, it was demonstrated that TSHR antibodies interact preferentially with TSHR A-subunit rather than to the holoreceptor expressed on the cell surface [31, 32]. Interestingly, functional TSHR is also present in extrathyroidal sites such as fat cells [33] and retrobulbar adipose tissue [34] that may be related to the pathology of GO. In addition, functional TSHR has been reported in bone cells [35, 36], although the issue remains controversial [37, 38].

Autoantibodies to TSHR comprise three different subtypes, thyroid stimulating antibodies (TSAbs), thyroid blocking antibodies (TSBAbs) and neutral antibodies [39]. TSAbs mimic the actions of TSH and initiate the TSHR signaling cascade leading to hyperthyroidism. In contrast, TSBAbs inhibit TSHR stimulation by TSH leading to a decrease of thyroid hormone secretion [39]. On the other hand, neutral TSHR antibodies neither block TSH binding nor stimulate the receptor and they do not induce cAMP generation [40]. The atomic structure of the ligand binding domain of hTSHR in complex with Fab fragment of human $\mathrm{mAb}$ with TSAb properties (M22) and human mAb with blocking activity (K1-70) has been determined [41, 42]. The interactions on TSHR of TSAbs and TSBAbs in the crystal structures show binding to overlapping, but different sites as well as to similar sites on the receptor [43].

\section{EXPERIMENTAL MURINE MODELS FOR GRAVES' DISEASE}

Experimental animal models of autoimmunity are based upon spontaneous or induced models. Unlike the occurrence of thyroiditis in nonhuman species, neither TSHR antibodies nor Graves' hyperthyroidism develop spontaneously in animals. Recent investigations into whether species more closely related to humans, i.e. the great apes, develop Graves' like syndromes have also proved negative $[44,45]$. Several different induced experimental mouse models have been described for Graves' disease. In contrast to induction of thyroiditis in animals initiated by injection of crude thyroid extracts [46-48] or immunization with protein and adjuvant [49-51], con- ventional approaches for immunization of different inbred mouse strains with recombinant hTSHR protein in adjuvants does not lead to induction of experimental autoimmune hyperthyroidism, although antibodies and $\mathrm{T}$ cell responses to the receptor protein were evident [52]. However, one study using a soluble, secreted ectodomain of hTSHR in female BALB/c mice, reported induction of stimulating antibodies and hyperthyroidism [53], but this has proved difficult to reproduce [54].

The first successful animal model for Graves' disease was developed by Shimojo and colleagues [55]. The rationale behind this model was based on the study in 1983 that showed induction of MHC II-expressing thyrocytes led to autoimmunity [56]. Thus, Shimojo and colleagues used transfected fibroblast cell lines (Lcells) that express both hTSHR and MHC class II antigens for injection to animals [55]. The model relied on multiple injections of AKR/N mice because these mice share the MHC class I and homologous MHC class II to transfected fibroblasts. Disease incidence in this model was $10-15 \%[55,57]$. The Shimojo model was improved by the addition of adjuvant [58]. Due to limitations of the model including, low rate of disease incidence, lack of TSAbs and nonspecific immune reactivity, further studies on the model have not been reported.

Because of difficulties associated with immunization of cells, most attention has been paid to genetic immunization. Outbred mice were injected with plasmid vector coding the hTSHR and this led to autoimmune hyperthyroidism, but the disease incidence continued to be low [59]. Despite of the simplicity of this model, it continues to be difficult to reproduce [57, 60, 61]. The model was improved by immunisation of transgenic HLA-DR3 mice in the NOD genetic background, lacking endogenous MHC class II, in conjunction with cytokines (IL-4 or GM-CSF) resulting in an increase in disease incidence to $30 \%$. The increased disease incidence was accompanied by focal lymphocytic infiltrates in the thyroid glands of some immune mice [62].

By changing the gene delivery method of hTSHR cDNA from plasmid to recombinant adenovirus in inbred mice (BALB/c), a large improvement was achieved in terms of disease incidence $(55 \%)$ and presence of TSAbs [32]. Modification of the immunogen to cDNA coding for hTSHR A-subunit instead of full length hTSHR led to an increase in the onset of hyperthyroidism in $70 \%$ of the animal groups [63]. This method has been reproduced in a number of other laboratories, including ours and thus, to date represents the most common model [64-67]. Briefly, female BALB/c mice (ages 7-8 week) were injected i.m. with the recombinant virus (50 $\mu$, containing $10^{9}$ particles) in PBS three times at three weekly intervals. Nevertheless, there are drawbacks of the adenovirus hTSHR A-subunit model of GD, where the viral coat proteins are exceptionally immunogenic leading to a large non-specific immune response to the virus [68]. Furthermore, the TSAbs decline rapidly after the last immunisation, hence long-term immunity is difficult to maintain in this model [69], our unpublished findings].

Studies on the adenovirus TSHR A-subunit model of Graves' disease have shown the essential role of B cells, not only for antibody secretion, but also as antigen presenting cells in the disease process [70]. Importantly, examination of environmental conditions by housing animals in pathogen free conditions compared to those housed in conventional clean, but non sterile conditions did not alter disease incidence suggesting negligible influence of microorganisms in this condition [71]. A dichotomy of Th1 versus Th2 type immune response in the Graves' disease model has been much more difficult to establish, since administration of exogenous cytokines such as IFN- $\gamma$, IL4 and IL10 leads to variable results compared to the presence of endogenous cytokines [72-74]. Moreover, IL17 does not appear to be essential for the induction of Graves' disease in the model [75]. However, Tregs appear to be important as their depletion enhances the degree of induced hyperthyroidism in $\mathrm{BALB} / \mathrm{c}$ mice [76]. 
The next step toward development of an animal model for Graves' disease was based on the immunization with plasmid vector containing hTSHR A-subunit cDNA in conjunction with close field electroporation [77, 78]. Using electroporation to transfer hTSHR A-subunit gene into the leg thigh muscles of BALB/c mice caused induction of hyperthyroidism in $70-80 \%$ of the immune mice. Most importantly, long-term immunity to the receptor was maintained for several months after the last injection [77, 78].

More recently, a new model has been described based upon mouse TSHR immunizations (rather than human TSHR immunizations in all the models described above) and hence represents a true, bona fide model for autoimmune Graves' disease. The model involves the transfer of TSHR autoimmunity from TSHR knockout (KO) mice to $\mathrm{T}$ cell deficient (nude) mice [79]. Briefly, wild type mice are tolerant to mouse TSHR, which is difficult to 'break' by immunization but, TSHR knockout mice do not develop tolerance to the receptor and hence amenable to induction of an immune response to the mouse receptor. However, no hyperthyroidism is expected because these mice lack the endogenous TSHR. By adoptive transfer of splenocytes from TSHR KO mice into nude mice, $50 \%$ of recipient mice were found to have TSHR Abs which persisted for 24 weeks. However, the majority of Abs were blocking antibodies and, by week 24 , those in whom stimulating antibodies had previously been detected had a dominant blocking antibody response. Nevertheless, two novel findings were reported in this model, long lasting immunity and a small degree of orbital inflammation. The model is very recent and awaits confirmation by other groups, but the fact that orbital changes were reported makes it an exciting model. These models are summarized in Table $\mathbf{1}$ and have been reviewed in last few years $[80,81]$.

\section{EXPERIMENTAL MOUSE MODELS FOR GRAVES' ORBITOPATHY}

Earlier models of GO have been reported, but remain to be substantiated $[82,83]$. The hTSHR A-subunit adenovirus model of Graves' disease does not lead to any orbital manifestations. The early decline in the induced anti-TSHR antibody, soon after the termination of adenovirus immunizations, may be responsible for the lack of GO as the animals never enter to the chronic stage of the disease. Antibody transfer models of hyperthyroidism are not 'true' models of autoimmune Graves' disease since the transfer was passive and induced acute but not chronic hyperthyroidism. However, both acute and chronic models induced by single or multiple injections of TSAb mAbs respectively do not appear to lead to any apparent signs of orbital inflammation in BALB/c or DR4 NOD transgenic mice $[64,84]$.

Recently, induction of mild orbital inflammation was also reported in the experimental model which was based on transferring TSHR autoimmunity from knockout (KO) mice to nude mice [79]. A common feature in two recent animal models of Graves' disease was that both the models show long-term persistence of induced immunity to the TSHR. Thus this may be a critical feature for development of complications of Graves' disease, such as orbital pathology $[78,79]$. We reasoned that chronic stimulation of TSHR may be essential to develop GO in animals undergoing induced Graves' disease. Improvements in the plasmid delivery with in vivo close field electroporation have resulted in increasing transfection efficiency and induction of a strong Ab response to TSHR. Importantly, this model generates long lasting immunity [77, 78]. Moreover, orbital fibrosis was apparent in the hyperthyroid disease animals induced by the electroporation methods [78].

Subsequently, further development of the model led to the induction of orbital pathology characterized by two distinct subtypes; orbital muscle inflammation and adipogenesis [85]. Classification of orbital pathology of GO patents into same two subtypes was already suggested [86]. The study into the GO experimental model revealed that all immune animals show orbital remodeling, manifest with orbital heterogeneity as found in patients with GO. The heterogeneity of orbital pathology in GO experimental model that recapitulate orbitopathy in patients was divided into two main subtypes; (i) majority of immune animals was characterized by infiltration of interstitial inflammatory cells into extraocular muscle (Fig. 1A). (ii) Concordantly, about $10 \%$ of immune mice showed expansion of retrobulbar adipose tissue and widely separating the orbital muscle fiber bundles (Fig. 1B). Importantly, two animals from different cohorts showed acute inflammation characterized by a large inflammatory infiltrate around the optic nerve as well as intense intermuscular lymphocytic infiltrate (Fig. 1C). Strikingly, a rare orbital manifestation in GO patients, chemosis, was readily detectable in some animals (Fig. 1D). There was no correlation with subtype of GO pathology or onset of chemosis with thyroid status or presence and subtype of anti-TSHR antibody in the model. Histological analysis of thyroid gland showed no sign of inflammation, similar to the findings with the adenovirus model of Graves' disease $[15,32,63,64]$.
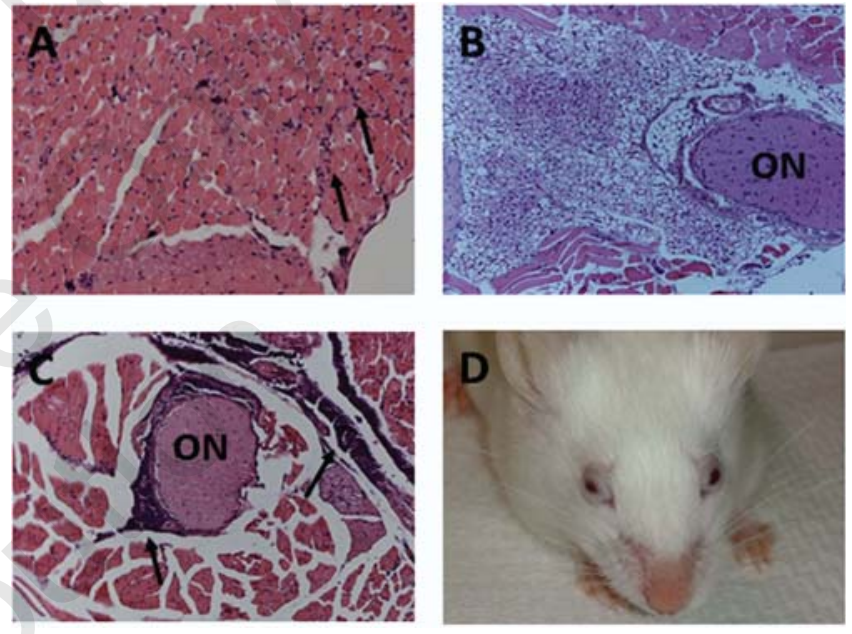

Fig. (1). Histological analysis of orbital tissue in mice undergoing GO. (A) Representative extraocular muscle from hTSHR-A subunit plasmidimmunized mice (x200) showing interstitial inflammatory infiltrate (arrowed). (B) Expansion of adipose tissue in retrobulbar fat (x100) to show adipose tissue widely separating the orbital muscle fiber bundles. (C) Optic nerve revealing dense perineural inflammatory infiltrate (arrowed), along with intense intermuscular lymphocytic infiltrate (arrowed) (x100). (D) Appearance of head region of hTSHR-A subunit plasmid-immunized mouse undergoing chemosis.

Apart from histological studies on the GO model, orbital manifestations were also examined by MRI. It had been postulated that differences in the orbital bone structure between humans and rodents [87] may not allow eyeball protrusion in the mice [88]. Despite the differences in the orbital anatomy, high-resolution in vivo MRI showed the unilateral proptosis as well as clear hypertrophy of the orbital muscles in some animals [85].

MRI clearly confirmed bilateral proptosis (Fig. 2A) in two immune animals. Moreover, the quantitative analysis confirmed a significant increase of extraorbital muscle volume in immune animals compared with age-matched controls. The MRI method for examination of orbital manifestation in the GO model was set up based on the clinical neuroradiological methods. As there were no scientific reports in the literature dealing with MRI analysis of extraorbital muscles in rodents, the MRI results required support by definitive histological analysis. To evaluate the MRI findings on enlarged extraorbital muscles, quantitative analysis was performed in the corresponding area of histological slides (Fig. 2B, C). Inter- 
Table 1. Experimental models of Graves' disease and GO developed over the past two decades. Only the models that reportedly induced autoimmune hyperthyroidism with presence of TSAbs are listed. hTSHR: human thyroid stimulating hormone receptor; mTSHR: mouse TSHR; TSAb: thyroid stimulating antibody; TBII: thyrotropin binding inhibiting immunoglobulin, N.D: not determined.

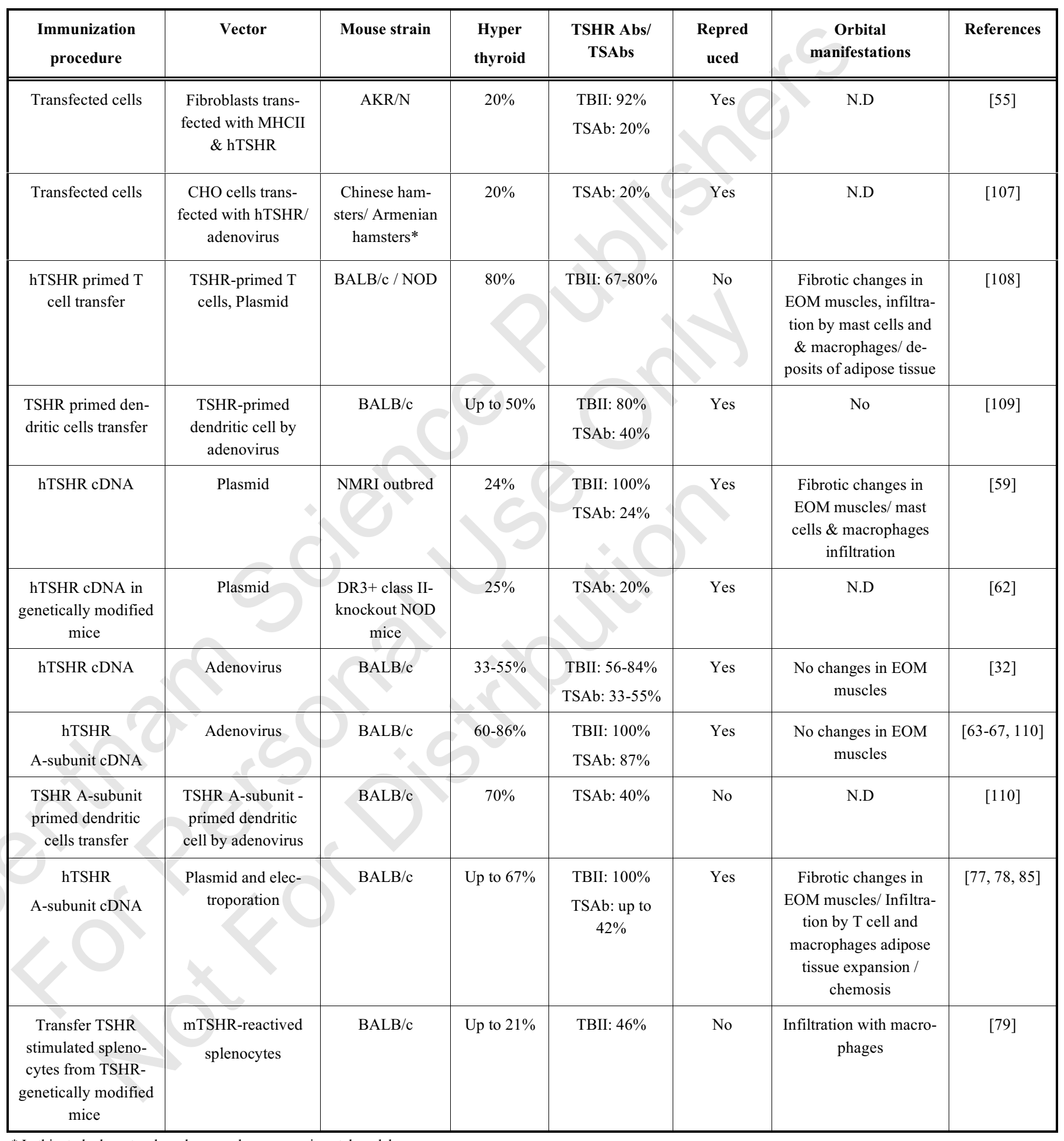

* In this study, hamsters have been used as an experimental model.

estingly, alignment of histological slides of extraorbital muscles with MR images confirmed the hypertrophy in orbital muscles [85]. Therefore, high resolution in vivo MRI method can be used for non invasive longitudinal studies to study the development of GO in the model.

\section{INSIGHTS FROM THE NEW GO MODEL}

Similar to other animal models of autoimmune disease, the experimental GO model has limitations including induction of TSBAbs and hypothyroidisms in most of the immune mice. However, it closely recapitulates particular aspects of the disease includ- 

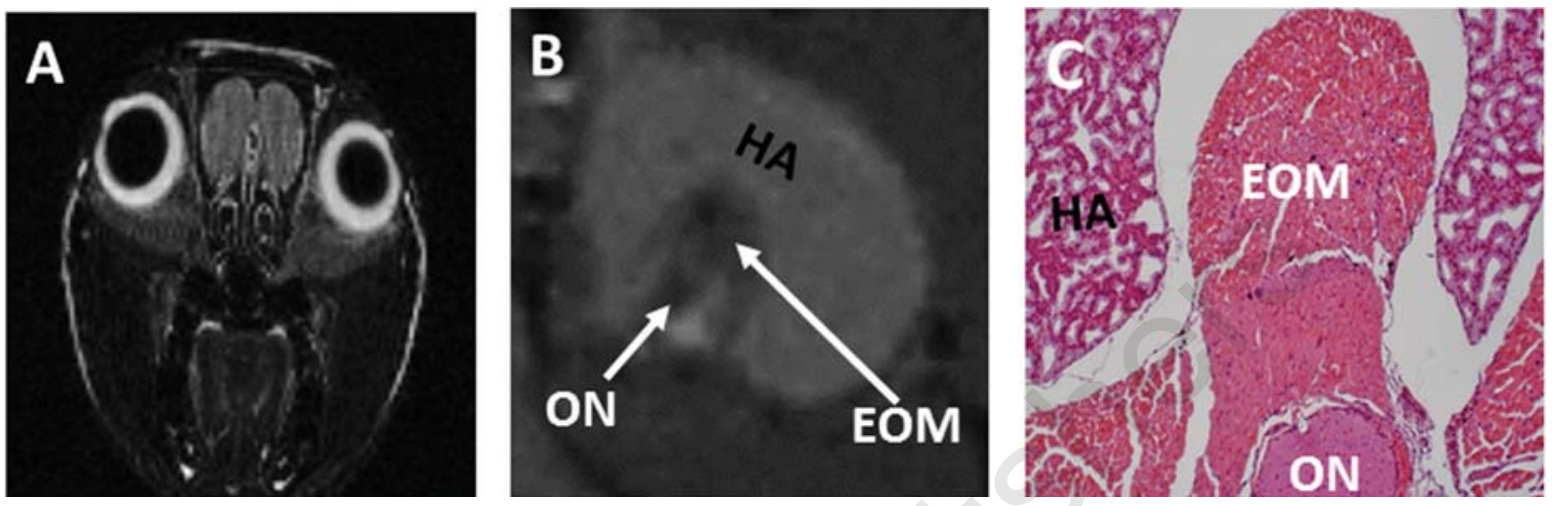

Fig. (2). MRI analysis of orbital tissue in mice undergoing GO. (A) Frontal MRI of the mouse head of a control animal. (B) Alignment of MRI scans showing structures of retrobulbar tissue in immune mouse with (C) the histological slide of the same area of the mouse orbital tissue. HA: Harderian gland, EOM: extraorbital muscles, ON: optic nerve.

ing heterogeneity of orbital condition and disease occurrence in hyperthyroid or hypothyroid state as found in patients. An important insight from the model is the primary role of the TSHR as an autoantigen in GO [85]. Evidence supporting the role of TSHR as a primary autoantigen in Graves' hyperthyroidism has been derived from early studies in Graves' disease [89-91]. However, the role of TSHR in the pathogenesis of GO remained uncertain [92, 93]. The demonstration from several laboratory studies in the GO patients further connected the orbital and thyroidal manifestations. However, confirmatory in vivo data has not been provided until the development of the new model [85].

Of particular interest, in most of immune animals, the thyroid function scored as hypothyroid status. Hypothyroidism status has been confirmed by thyroid gland atrophy on histological analysis, total T4 level in the immune mice sera and significant weight gain. Examination of thyroid glands of GO experimental model by H\&E staining showed a typical pattern of hypothyroidism, including thinning of the thyroid epithelial cells, a characteristic sign of underactivity of the gland. The data also confirmed that the subtype of induced anti-TSHR antibodies was dominated by blocking antibodies while few immune animals showed positivity for stimulating Abs. It was not unexpected finding since it was already shown that alteration of the antigenic dose (adenovirus hTSHR A-subunit as immunogen) resulted in change of the spectrum of anti-TSHR antibodies from TSAbs to TSBAbs [94]. Importantly, irrespective of whether the anti-TSHR response was blocking or stimulating antibodies, the animals developed orbital complications, indicating that disease development was not solely dependent on the subtype of antibody. Further studies into the induction of anti-TSHR antibody subtypes by serial bleeding in longitudinal studies showed that the TSBAbs evolved early during immunisation and persisted for months [85]. The longitudinal studies also indicate that the subtype of antibody spectrum to TSHR in the model is not prone to changing from stimulating to blocking antibodies or vice versa during the course of disease, as occasionally reported in patients [95-100]. The difference between subtypes of TSHR Abs in this study (TSBAbs) and in the adenovirus model (TSAbs) [32, 80, 81] may contribute to the orbital pathological outcome in the two models.. Apparently, the mechanism by which TSBAbs and hypothyroidism influence the pathogenesis of GO is not clear [100] and needs to be studied in more depth on GO experimental model.

The GO model is a relatively new model that takes several months to develop. As the model is developed further and reproduced in other laboratories will lead to new knowledge on the pathogenensis of GO. In addition, the experimental mouse model for GO is a promising vehicle for translational studies of potential novel therapeutic agents and drug development.
As mentioned earlier, apart from classical therapeutic strategies, there are a number of novel approaches for targeted biological therapy in GO (i) systemic dampening the immune response dysregulation [101] and (ii) antagonizing excessive TSHR signaling [102, 103]. Rituximab (RTX), anti-CD20 mAb, is a well-studied example for the targeted therapy with modulation in immune response. Although, the significant effect of RTX in activity and severity of GO patients has been recently documented [104] which has been confirmed by a randomized clinical trial (RCT) [105]; However, another recent randomized RTX trail in moderate-to-severe GO patients has failed to support the role of RTX as a therapeutic agent for treatment of GO [106]. In addition, phase two of multicenter control trial with humanized anti-IGF-1R blocking mAb, teprotumumab is ongoing (www.clinicaltrials.gov/ct2/show/record/ NCT01868997), The experimental GO model will open a new avenue for translational studies of these novel therapeutic agents. These studies will no doubt facilitate the initiation of randomized clinical trials of novel agents in patients with GO.

\section{CONCLUSION}

Over the past two decades since the first mouse model of Graves' disease was developed, a variety of better models with higher degrees of disease incidence and reproducibility have been described. The models have led to a greater understanding of the TSAbs developed as mAbs and their pathogenic capability in inducing hyperthyroidism. Finally, the recent extrapolation of the model to develop the orbital inflammatory condition of GO will add much to the understanding of this debilitating condition and evaluation of novel treatments and therapies targeted specifically to this disease.

\section{STATEMENT}

All animal studies conducted under license from United Kingdom Home Office with accepted standards of humane animal care.

\begin{tabular}{|c|c|c|}
\hline \multicolumn{3}{|c|}{ ABBREVIATIONS } \\
\hline Abs & $=$ & antibodies \\
\hline AITD & $=$ & autoimmune thyroid disease \\
\hline GAGs & $=$ & glycosaminoglycans \\
\hline GO & $=$ & Graves' orbitopathy \\
\hline GWAS & $=$ & genome-wide association study \\
\hline HLA & $=$ & human leukocyte antigen \\
\hline hTSHR & $=$ & human thyroid stimulating hormone receptor \\
\hline LRR & $=$ & leucine rich repeat \\
\hline mAbs & $=$ & monoclonal antibodies \\
\hline MRI & $=$ & magnetic resonance imaging \\
\hline
\end{tabular}




$$
\begin{aligned}
& \text { mTSHR }=\text { mouse TSHR } \\
& \text { SNP }=\text { single nucleotide polymorphism } \\
& \text { TBII = thyrotropin binding inhibiting immunoglobulin } \\
& \mathrm{TSAb}=\text { thyrotropin stimulating antibody } \\
& \text { TSBAbs = thyrotropin stimulating blocking antibody } \\
& \text { TSHR }=\text { thyrotropin hormone receptor }
\end{aligned}
$$

\section{CONFLICT OF INTEREST}

The authors confirm that this article content has no conflicts of interest.

\section{ACKNOWLEDGEMENTS}

Declared none.

\section{REFERENCES}

[1] Jacobson DL, Gange SJ, Rose NR, Graham NM. Epidemiology and estimated population burden of selected autoimmune diseases in the United States. Clin Immunol Immunopathol 1997; 84: 223-43.

[2] Hollowell JG, Staehling NW, Flanders WD, et al. Serum TSH, $\mathrm{T}(4)$, and thyroid antibodies in the United States population (1988 to 1994): National Health and Nutrition Examination Survey (NHANES III). J Clin Endocrinol Metab 2002; 87: 489-99.

[3] Brix TH, Hegedus L. Twins as a tool for evaluating the influence of genetic susceptibility in thyroid autoimmunity. Ann Endocrinol (Paris) 2011; 72: 103-7.

[4] Brix TH, Hegedus L, Gardas A, Banga JP, Nielsen CH. Monozygotic twin pairs discordant for Hashimoto's thyroiditis share a high proportion of thyroid peroxidase autoantibodies to the immunodominant region A. Further evidence for genetic transmission of epitopic "fingerprints". Autoimmunity 2011; 44: 188-94.

[5] Dechairo BM, Zabaneh D, Collins J, et al. Association of the TSHR gene with Graves' disease: the first disease specific locus. Eur J Hum Genet 2005; 13: 1223-30.

[6] Ban Y, Greenberg DA, Concepcion E, Skrabanek L, Villanueva R, Tomer Y. Amino acid substitutions in the thyroglobulin gene are associated with susceptibility to human and murine autoimmune thyroid disease. Proc Natl Acad Sci USA 2003; 100: 15119-24.

[7] Jacobson EM, Huber A, Tomer Y. The HLA gene complex in thyroid autoimmunity: from epidemiology to etiology. J Autoimmun 2008; 30: 58-62.

[8] Jacobson EM, Concepcion E, Oashi T, Tomer Y. A Graves' disease-associated Kozak sequence single-nucleotide polymorphism enhances the efficiency of CD40 gene translation: a case for translational pathophysiology. Endocrinology 2005; 146: 2684-91.

[9] Weetman AP. The genetics of autoimmune thyroid disease. Horm Metab Res 2009; 41: 421-5.

[10] Cooper JD, Simmonds MJ, Walker NM, et al. Seven newly identified loci for autoimmune thyroid disease. Hum Mol Genet 2012; 21: 5202-8.

[11] Tomer Y. Mechanisms of autoimmune thyroid diseases: from genetics to epigenetics. Annu Rev Pathol 2014; 9: 147-56.

[12] Stefan M, Wei C, Lombardi A, et al. Genetic-epigenetic dysregulation of thymic TSH receptor gene expression triggers thyroid autoimmunity. Proc Natl Acad Sci USA 2014; 111: 12562-7.

[13] Burek CL, Talor MV. Environmental triggers of autoimmune thyroiditis. J Autoimmun 2009; 33: 183-9.

[14] Rose NR, Bonita R, Burek CL. Iodine: an environmental trigger of thyroiditis. Autoimmun Rev 2002; 1: 97-103.

[15] McLachlan SM, Rapoport B. Breaking tolerance to thyroid antigens: changing concepts in thyroid autoimmunity. Endocr Rev 2014; 35: 59-105.

[16] Marcocci C, Kahaly GJ, Krassas GE, et al. Selenium and the course of mild Graves' orbitopathy. N Engl J Med 2011; 364: 192031.

[17] Wiersinga WM. Smoking and thyroid. Clin Endocrinol (Oxf) 2013; 79: 145-51.

[18] Chng CL, Lai OF, Chew CS, et al. Hypoxia increases adipogenesis and affects adipocytokine production in orbital fibroblasts-a possible explanation of the link between smoking and Graves' ophthalmopathy. Int J Ophthalmol 2014; 7: 403-7.
Root-Bernstein R, Fairweather D. Complexities in the relationship between infection and autoimmunity. Curr Allergy Asthma Rep 2014; 14: 407

Hargreaves CE, Grasso M, Hampe CS, et al. Yersinia enterocolitica provides the link between thyroid-stimulating antibodies and their germline counterparts in Graves' disease. J Immunol 2013; 190: 5373-81.

Weetman AP. Grave's disease 1835-2002. Horm Res 2003; 59 (Suppl 1): 114-8.

Bahn RS. Graves' ophthalmopathy. N Eng J Med 2010; 362: 72638.

[23] Wiersinga WM, Bartalena L. Epidemiology and prevention of Graves' ophthalmopathy. Thyroid 2002; 12: 855-60.

[24] Rapoport B, McLachlan SM. The thyrotropin receptor in Graves' disease. Thyroid 2007; 17: 911-22.

[25] Tanaka K, Chazenbalk GD, McLachlan SM, Rapoport B. Thyrotropin receptor cleavage at site 1 involves two discontinuous segments at each end of the unique 50-amino acid insertion. J Biol Chem 1999; 274: 2093-6.

[26] Kajita Y, Rickards CR, Buckland PR, Howells RD, Rees Smith B. Analysis of thyrotropin receptors by photoaffinity labelling. Orientation of receptor subunits in the cell membrane. Biochem J 1985; 227: 413-20.

[27] Loosfelt H, Pichon C, Jolivet A, et al. Two-subunit structure of the human thyrotropin receptor. Proc Natl Acad Sci USA 1992; 89: 3765-9.

[28] Misrahi M, Ghinea N, Sar S, et al. Processing of the precursors of the human thyroid-stimulating hormone receptor in various eukaryotic cells (human thyrocytes, transfected L cells and baculovirus-infected insect cells). Eur J Biochem 1994; 222: 711-9.

[29] Couet J, Sar S, Jolivet A, Hai MT, Milgrom E, Misrahi M. Shedding of human thyrotropin receptor ectodomain. Involvement of a matrix metalloprotease. J Biol Chem 1996; 271: 4545-52.

[30] Tanaka K, Chazenbalk GD, McLachlan SM, Rapoport B. The shed thyrotropin receptor is primarily a carboxyl terminal truncated form of the A subunit, not the entire A subunit. Mol Cell Endocrinol 1999; 150: 113-9.

[31] Chazenbalk GD, Pichurin P, Chen CR, et al. Thyroid-stimulating autoantibodies in Graves disease preferentially recognize the free A subunit, not the thyrotropin holoreceptor. J Clin Invest 2002; 110: 209-17.

[32] Nagayama $\mathrm{Y}$, Kita-Furuyama M, Ando T, et al. A novel murine model of Graves' hyperthyroidism with intramuscular injection of adenovirus expressing the thyrotropin receptor. J Immunol 2002; 168: 2789-94.

[33] Mullin BR, Lee G, Ledley FD, Winland RJ, Kohn LD. Thyrotropin interactions with human fat cell membrane preparations and the finding of soluble thyrotropin binding component. Biochem Biophys Res Commun 1976; 69: 55-62.

[34] Davies TF. The impact of peptide hormone receptor research on clinical medicine. J R Coll Phys Lond 1978; 12: 379-97.

[35] Abe E, Marians RC, $\mathrm{Yu} \mathrm{W,} \mathrm{et} \mathrm{al.} \mathrm{TSH} \mathrm{is} \mathrm{a} \mathrm{negative} \mathrm{regulator} \mathrm{of}$ skeletal remodeling. Cell 2003; 115: 151-62.

[36] Ma R, Morshed S, Latif R, Zaidi M, Davies TF. The influence of thyroid-stimulating hormone and thyroid-stimulating hormone receptor antibodies on osteoclastogenesis. Thyroid 2011; 21: 897906.

[37] Bassett JH, Williams AJ, Murphy E, et al. A lack of thyroid hormones rather than excess thyrotropin causes abnormal skeletal development in hypothyroidism. Mol Endocrinol 2008; 22: 501-12.

[38] Tsai JA, Janson A, Bucht E, et al. Weak evidence of thyrotropin receptors in primary cultures of human osteoblast-like cells. Calcif Tissue Int 2004; 74: 486-91.

[39] Rees Smith B, McLachlan SM, Furmaniak J. Autoantibodies to the thyrotropin receptor. Endocr Rev 1988; 9: 106-21.

[40] Morshed SA, Ando T, Latif R, Davies TF. Neutral antibodies to the TSH receptor are present in Graves' disease and regulate selective signaling cascades. Endocrinology 2010; 151: 5537-49.

[41] Sanders J, Chirgadze DY, Sanders P, et al. Crystal structure of the TSH receptor in complex with a thyroid-stimulating autoantibody. Thyroid 2007; 17: 395-410.

[42] Sanders P, Young S, Sanders J, et al. Crystal structure of the TSH receptor (TSHR) bound to a blocking-type TSHR autoantibody. J Mol Endocrinol 2011; 46: 81-99. 
[43] Nunez MR, Sanders J, Sanders P, et al. Similarities and differences in interactions of thyroid stimulating and blocking autoantibodies with the TSH receptor. J Mol Endocrinol 2012; 49: 137-51.

[44] McLachlan SM, Alpi K, Rapoport B. Review and hypothesis: does Graves' disease develop in non-human great apes? Thyroid 2011; 21: 1359-66.

[45] Aliesky H, Courtney CL, Rapoport B, McLachlan SM. Thyroid autoantibodies are rare in nonhuman great apes and hypothyroidism cannot be attributed to thyroid autoimmunity. Endocrinology 2013; 154: 4896-907.

[46] Terplan KL, Witebsky E, Rose NR, Paine JR, Egan RW. Experimental thyroiditis in rabbits, guinea pigs and dogs, following immunization with thyroid extracts of their own and of heterologous species. Am J Pathol 1960; 36: 213-39.

[47] Witebsky E, Rose NR, Terplan K, Paine JR, Egan RW. Chronic thyroiditis and autoimmunization. J Am Med Assoc 1957; 164: 1439-47.

[48] Pudifin DJ, Duursma J, Brain P. Experimental autoimmune thyroiditis in the vervet monkey. Clin Exp Immunol 1977; 29: 256-60.

[49] Esquivel PS, Rose NR, Kong YC. Induction of autoimmunity in good and poor responder mice with mouse thyroglobulin and lipopolysaccharide. J Exp Med 1977; 145: 1250-63.

[50] McLachlan SM, Atherton MC, Nakajima Y, et al. Thyroid peroxidase and the induction of autoimmune thyroid disease. Clin Exp Immunol 1990; 79: 182-8.

[51] Ng HP, Banga JP, Kung AW. Development of a murine model of autoimmune thyroiditis induced with homologous mouse thyroid peroxidase. Endocrinology 2004; 145: 809-16.

[52] Carayanniotis G, Huang GC, Nicholson LB, et al. Unaltered thyroid function in mice responding to a highly immunogenic thyrotropin receptor: implications for the establishment of a mouse model for Graves' disease. Clin Exp Immunol 1995; 99: 294-302.

[53] Kaithamana S, Fan J, Osuga Y, Liang SG, Prabhakar BS. Induction of experimental autoimmune Graves' disease in BALB/c mice. $J$ Immunol 1999; 163: 5157-64

[54] Wang SH, Carayanniotis G, Zhang Y, Gupta M, McGregor AM, Banga JP. Induction of thyroiditis in mice with thyrotropin receptor lacking serologically dominant regions. Clin Exp Immunol 1998; 113: 119-25.

[55] Shimojo N, Kohno Y, Yamaguchi K, et al. Induction of Graveslike disease in mice by immunization with fibroblasts transfected with the thyrotropin receptor and a class II molecule. Proc Natl Acad Sci USA 1996; 93: 11074-9.

[56] Bottazzo GF, Pujol-Borrell R, Hanafusa T, Feldmann M. Role of aberrant HLA-DR expression and antigen presentation in induction of endocrine autoimmunity. Lancet 1983; 2: 1115-9.

[57] Rao PV, Watson PF, Weetman AP, Carayanniotis G, Banga JP. Contrasting activities of thyrotropin receptor antibodies in experimental models of Graves' disease induced by injection of transfected fibroblasts or deoxyribonucleic acid vaccination. Endocrinology 2003; 144: 260-6.

[58] Kita M, Ahmad L, Marians RC, et al. Regulation and transfer of a murine model of thyrotropin receptor antibody mediated Graves' disease. Endocrinology 1999; 140: 1392-8.

[59] Costagliola S, Many MC, Denef JF, Pohlenz J, Refetoff S, Vassart G. Genetic immunization of outbred mice with thyrotropin receptor cDNA provides a model of Graves' disease. J Clin Invest 2000; 105: 803-11.

[60] Pichurin P, Yan XM, Farilla L, et al. Naked TSH receptor DNA vaccination: A TH1 T cell response in which interferon-gamma production, rather than antibody, dominates the immune response in mice. Endocrinology 2001; 142: 3530-6.

[61] Pichurin P, Pichurina O, Chazenbalk GD, et al. Immune deviation away from Th1 in interferon-gamma knockout mice does not enhance TSH receptor antibody production after naked DNA vaccination. Endocrinology 2002; 143: 1182-9.

[62] Flynn JC, Rao PV, Gora M, et al. Graves' hyperthyroidism and thyroiditis in HLA-DRB1*0301 (DR3) transgenic mice after immunization with thyrotropin receptor DNA. Clin Exp Immunol 2004; 135: 35-40

[63] Chen CR, Pichurin P, Nagayama Y, Latrofa F, Rapoport B, McLachlan SM. The thyrotropin receptor autoantigen in Graves disease is the culprit as well as the victim. J Clin Invest 2003; 111 : 1897-904.

[64] Gilbert JA, Gianoukakis AG, Salehi S, et al. Monoclonal pathogenic antibodies to the thyroid-stimulating hormone receptor in
Graves' disease with potent thyroid-stimulating activity but differential blocking activity activate multiple signaling pathways. J Immunol 2006; 176: 5084-92.

[65] Land KJ, Gudapati P, Kaplan MH, Seetharamaiah GS. Differential requirement of signal transducer and activator of transcription-4 (Stat4) and Stat6 in a thyrotropin receptor-289-adenovirus-induced model of Graves' hyperthyroidism. Endocrinology 2006; 147: 111 9.

[66] Wu L, Xun L, Yang J, et al. Induction of murine neonatal tolerance against Graves' disease using recombinant adenovirus expressing the TSH receptor A-subunit. Endocrinology 2011; 152: 1165-71.

[67] Ye F, Hou P, Wu X, et al. The significance of immune-related molecule expression profiles in an animal model of Graves' disease. Autoimmunity 2012; 45: 143-52.

[68] Veron P, Leborgne C, Monteilhet V, et al. Humoral and cellular capsid-specific immune responses to adeno-associated virus type 1 in randomized healthy donors. J Immunol 2012; 188: 6418-24.

[69] McLachlan SM, Aliesky HA, Chen CR, Rapoport B. Role of selftolerance and chronic stimulation in the long-term persistence of adenovirus-induced thyrotropin receptor antibodies in wild-type and transgenic mice. Thyroid 2012; 22: 931-7.

[70] Pichurin P, Aliesky H, Chen CR, Nagayama Y, Rapoport B, McLachlan SM. Thyrotrophin receptor-specific memory $\mathrm{T}$ cell responses require normal B cells in a murine model of Graves' disease. Clin Exp Immunol 2003; 134: 396-402.

[71] Nagayama Y, McLachlan SM, Rapoport B, Niwa M. A major role for non-major histocompatibility complex genes but not for microorganisms in a novel murine model of Graves' hyperthyroidism. Thyroid 2003; 13: 233-8.

[72] Nagayama Y, Saitoh O, McLachlan SM, Rapoport B, Kano H, Kumazawa Y. TSH receptor-adenovirus-induced Graves' hyperthyroidism is attenuated in both interferon-gamma and interleukin-4 knockout mice; implications for the Th1/Th2 paradigm. Clin Exp Immunol 2004; 138: 417-22

[73] Nagayama Y, Mizuguchi H, Hayakawa T, Niwa M, McLachlan SM, Rapoport B. Prevention of autoantibody-mediated Graves'-like hyperthyroidism in mice with IL-4, a Th2 cytokine. J Immunol 2003; 170: 3522-7.

[74] Ueki I, Abiru N, Kawagoe K, Nagayama Y. Interleukin 10 deficiency attenuates induction of anti-TSH receptor antibodies and hyperthyroidism in a mouse Graves' model. J Endocrinol 2011; 209: 353-7.

[75] Horie I, Abiru N, Saitoh O, et al. Distinct role of T helper Type 17 immune response for Graves' hyperthyroidism in mice with different genetic backgrounds. Autoimmunity 2011; 44: 159-65.

[76] Saitoh O, Abiru N, Nakahara M, Nagayama Y. CD8+CD122+ T cells, a newly identified regulatory $\mathrm{T}$ subset, negatively regulate Graves' hyperthyroidism in a murine model. Endocrinology 2007; 148: 6040-6.

[77] Kaneda T, Honda A, Hakozaki A, Fuse T, Muto A, Yoshida T. An improved Graves' disease model established by using in vivo electroporation exhibited long-term immunity to hyperthyroidism in BALB/c mice. Endocrinology 2007; 148: 2335-44.

[78] Zhao SX, Tsui S, Cheung A, Douglas RS, Smith TJ, Banga JP Orbital fibrosis in a mouse model of Graves' disease induced by genetic immunization of thyrotropin receptor cDNA. J Endocrinol 2011; 210: 369-77.

[79] Nakahara M, Johnson K, Eckstein A, et al. Adoptive transfer of antithyrotropin receptor (TSHR) autoimmunity from TSHR knockout mice to athymic nude mice. Endocrinology 2012; 153: 203442.

[80] Dağdelen Su, Kong Y-cM, Banga JP. Toward better models of hyperthyroid Graves' disease. Endocrinol Metab Clin North Am 2009; 38: 343-54.

[81] Wiesweg B, Johnson KT, Eckstein AK, Berchner-Pfannschmidt U. Current insights into animal models of Graves' disease and orbitopathy. Horm Metab Res 2013; 45: 549-55.

[82] Baker G, Mazziotti G, von Ruhland C, Ludgate M. Reevaluating thyrotropin receptor-induced mouse models of graves' disease and ophthalmopathy. Endocrinology 2005; 146: 835-44.

[83] Bahn RS. News and views: at long last, an animal model of graves orbitopathy. Endocrinology 2013; 154: 2989-91

[84] Flynn JC, Gilbert JA, Meroueh C, et al. Chronic exposure in vivo to thyrotropin receptor stimulating monoclonal antibodies sustains high thyroxine levels and thyroid hyperplasia in thyroid autoimmu- 
nity-prone HLA-DRB1*0301 transgenic mice. Immunology 2007; 122: 261-7.

[85] Moshkelgosha S, So PW, Deasy N, Diaz-Cano S, Banga JP. Cutting edge: retrobulbar inflammation, adipogenesis, and acute orbital congestion in a preclinical female mouse model of graves' orbitopathy induced by thyrotropin receptor plasmid-in vivo electroporation. Endocrinology 2013; 154: 3008-15.

[86] Kuriyan AE, Woeller CF, O'Loughlin CW, Phipps RP, Feldon SE. Orbital fibroblasts from thyroid eye disease patients differ in proliferative and adipogenic responses depending on disease subtype. Invest Ophthalmol Vis Sci 2013; 54: 7370-7.

[87] Smith RS. Systematic evaluation of the mouse eye : anatomy, pathology, and biomethods. Boca Raton, London: CRC Press 2002.

[88] Wiersinga WM. Autoimmunity in Graves' ophthalmopathy: the result of an unfortunate marriage between TSH receptors and IGF1 receptors? J Clin Endocrinol Metab 2011; 96: 2386-94.

[89] Adams DD, Purves HD. Abnormal responses to the assay of thyrotrophin. Proc Univ Otago Med Sch 1956; 34: 11-2.

[90] Kriss JP, Pleshakov V, Chien JR. Isolation and Identification of the Long-Acting Thyroid Stimulator and Its Relation to Hyperthyroidism and Circumscribed Pretibial Myxedema. J Clin Endocrinol Metab 1964; 24: 1005-28

[91] Smith BR, Hall R. Binding of thyroid stimulators to thyroid membranes. FEBS Lett 1974; 42: 301-4.

[92] Diana T, Brown R, Bossowski A, et al. Clinical relevance of thyroid-stimulating autoantibodies in pediatric graves' disease - a multicenter study. J Clin Endocrinol Metab 2014: 99(5): 1648-55.

[93] Wall JR. Thyroid function. Pathogenesis of Graves ophthalmopathy--a role for TSH-R? Nat Rev Endocrinol 2014; 10: 256-8.

[94] Chen CR, Pichurin P, Chazenbalk GD, et al. Low-dose immunization with adenovirus expressing the thyroid-stimulating hormone receptor A-subunit deviates the antibody response toward that of autoantibodies in human Graves' disease. Endocrinology 2004; 145: 228-33.

[95] Takeda K, Takamatsu J, Kasagi K, et al. Development of hyperthyroidism following primary hypothyroidism: a case report with changes in thyroid-related antibodies. Clin Endocrinol (Oxf) 1988; 28: 341-4.

[96] Cho BY, Shong YK, Lee HK, Koh CS, Min HK. Graves' hyperthyroidism following primary hypothyroidism: sequential changes in various activities of thyrotropin receptor antibodies. Acta Endocrinol (Copenh) 1989; 120: 447-50.

[97] Takasu N, Yamada T, Sato A, et al. Graves' disease following hypothyroidism due to Hashimoto's disease: studies of eight cases. Clin Endocrinol (Oxf) 1990; 33: 687-98.

[98] Kraiem Z, Baron E, Kahana L, Sadeh O, Sheinfeld M. Changes in stimulating and blocking TSH receptor antibodies in a patient undergoing three cycles of transition from hypo to hyper-thyroidism and back to hypothyroidism. Clin Endocrinol (Oxf) 1992; 36: 2114.

[99] Takasu N, Matsushita M. Changes of TSH-stimulation blocking antibody (TSBAb) and thyroid stimulating antibody (TSAb) over 10 years in 34 TSBAb-positive patients with hypothyroidism and in 98 TSAb-positive graves' patients with hyperthyroidism: reevaluation of TSBAb and TSAb in TSH-receptor-antibody (TRAb)positive patients. J Thyroid Res 2012; 2012: 182176.

[100] McLachlan SM, Rapoport B. Thyrotropin-blocking autoantibodies and thyroid-stimulating autoantibodies: potential mechanisms involved in the pendulum swinging from hypothyroidism to hyperthyroidism or vice versa. Thyroid 2013; $23: 14-24$.

[101] Banga JP, Nielsen CH, Gilbert JA, El Fassi D, Hegedus L. Application of new therapies in Graves' disease and thyroid-associated ophthalmopathy: animal models and translation to human clinical trials. Thyroid 2008; 18: 973-81.

[102] Neumann S, Nir EA, Eliseeva E, et al. A selective TSH receptor antagonist inhibits stimulation of thyroid function in female mice. Endocrinology 2014; 155: 310-4.

[103] van Zeijl CJ, van Koppen CJ, Surovtseva OV, et al. Complete inhibition of rhTSH-, Graves' disease IgG-, and M22-induced cAMP production in differentiated orbital fibroblasts by a lowmolecular-weight TSHR antagonist. J Clin Endocrinol Metab 2012; 97: E781-5.

[104] Salvi M, Vannucchi G, Beck-Peccoz P. Potential utility of rituximab for Graves' orbitopathy. J Clin Endocrinol Metab 2013; 98: 4291-9.

[105] Salvi M, Vannucchi G, Curro N, et al. Efficacy of B-Cell Targeted Therapy with Rituximab in Patients with Active Moderate-Severe Graves' Orbitopathy: A Randomized Controlled Study. J Clin Endocrinol Metab 2014: jc20143014.

[106] Stan MN, Garrity JA, Carranza Leon BG, Prabin T, Bradley EA, Bahn RS. Randomized controlled trial of rituximab in patients with graves' orbitopathy. J Clin Endocrinol Metab 2015: 100(2): 432-41.

[107] Ando T, Imaizumi M, Graves P, Unger P, Davies TF. Induction of thyroid-stimulating hormone receptor autoimmunity in hamsters. Endocrinology 2003; 144: 671-80.

[108] Many MC, Costagliola S, Detrait M, Denef J-F, Vassart G, Ludgate M. Development of an animal model of autoimmune thyroid eye disease. J Immunol 1999; 162: 4966-74.

[109] Kita-Furuyama M, Nagayama Y, Pichurin P, McLachlan SM, Rapoport B, Eguchi K. Dendritic cells infected with adenovirus expressing the thyrotrophin receptor induce Graves' hyperthyroidism in BALB/c mice. Clin Exp Immunol 2003; 131: 234-40.

[110] Mizutori Y, Saitoh O, Eguchi K, Nagayama Y. Adenovirus encoding the thyrotropin receptor A-subunit improves the efficacy of dendritic cell-induced Graves' hyperthyroidism in mice. J Autoimmun 2006; 26: 32-6.
Received: January 27, 2015

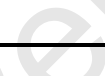

Accepted: March 13, 2015 